\title{
Leveraging open hardware to alleviate the burden of COVID-19 on global health systems
}

\author{
Andre Maia Chagas $\oplus^{1,2,3 *}$, Jennifer C. Molloy $\oplus^{3,4 *}$, Lucia L. Prieto-Godino $\oplus^{2,5,6 *}$, \\ Tom Baden $\mathbb{D}^{1,2,6,7} *$
}

1 Sussex Neuroscience, School of Life Sciences, University of Sussex, Brighton, United Kingdom, 2 TReND in Africa, Brighton, United Kingdom, 3 Gathering for Open Science Hardware, 4 Department of Chemical Engineering and Biotechnology, University of Cambridge, Cambridge, United Kingdom, 5 The Francis Crick Institute, London, United Kingdom, 6 FENS-KAVLI Network of Excellence, 7 Institute for Ophthalmic Research, University of Tübingen, Tübingen, Germany

* a.maia-chagas@ sussex.ac.uk (AMC); jcm80@cam.ac.uk (JCM); lucia.prietogodino@ crick.ac.uk (LLPG); t. baden@sussex.ac.uk (TB)

Check for updates

\section{f open access}

Citation: Maia Chagas A, Molloy JC, Prieto-Godino LL, Baden T (2020) Leveraging open hardware to alleviate the burden of COVID-19 on global health systems. PLoS Biol 18(4): e3000730. https://doi. org/10.1371/journal.pbio.3000730

Published: April 24, 2020

Copyright: @ 2020 Maia Chagas et al. This is an open access article distributed under the terms of the Creative Commons Attribution License, which permits unrestricted use, distribution, and reproduction in any medium, provided the original author and source are credited.

Funding: Funding was provided by the European Research Council (ERC-StG "NeuroVisEco" 677687 to TB and ERC StG "EvoNeuroCircuit" 802531 to LLPG), the UKRI (BBSRC, BB/R014817/ 1 to TB; MRC, MC_PC_15071 to TB; EPSRC EP/ R014000/1 to JCM), the Leverhulme Trust (PLP2017-005 to TB), the Lister Institute for Preventive Medicine (to TB), the Shuttleworth Foundation (to JCM), and The Francis Crick Institute (to LLPG). The funders had no role in study design, data collection and analysis, decision to publish, preparation of the manuscript.

Competing interests: The authors have declared that no competing interests exist.

\section{Abstract}

With the current rapid spread of COVID-19, global health systems are increasingly overburdened by the sheer number of people that need diagnosis, isolation and treatment. Shortcomings are evident across the board, from staffing, facilities for rapid and reliable testing to availability of hospital beds and key medical-grade equipment. The scale and breadth of the problem calls for an equally substantive response not only from frontline workers such as medical staff and scientists, but from skilled members of the public who have the time, facilities and knowledge to meaningfully contribute to a consolidated global response. Here, we summarise community-driven approaches based on Free and Open Source scientific and medical Hardware (FOSH) as well as personal protective equipment (PPE) currently being developed and deployed to support the global response for COVID-19 prevention, patient treatment and diagnostics.

\section{Introduction}

In recent days and weeks, governments around the world have called upon industry to address key shortcomings in the global response to COVID-19-for example to produce more personal protective equipment (PPE), ventilators and diagnostic tools $[1,2]$. While this is an important part of any country's response, the capacity of existing industry to meet the scale of the challenge is likely insufficient [3-5]. Moreover, this approach will first address shortages locally where relevant industry is based, rather than globally, and medical grade equipment and kits emerging from this process will be costly, at a time where the economy is taking a big hit. Clearly, product innovation and novel manufacturing pipelines are required.

Here, one complementary access route to much needed tools and equipment is Free and

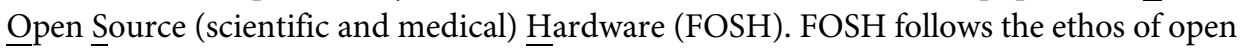
source software, where all blueprints for a tool are made freely available under appropriate licenses so that anyone can study, learn, modify, customize and commercialize them [6,7]. Studies and practical experience with FOSH have shown key benefits that are paramount for disaster situations: fast and distributed development based on the contributions of many 
people who are for the most part working remotely $[8,9]$.This is advantageous given the social distancing measures in place in many COVID-19 affected countries. The typically much lower implementation costs of FOSH [10] and easy adaptability to local resources are key further benefits of an open hardware approach.

Finally, and perhaps most importantly, any new hardware designs or improvements thereof are by their very definition globally available. Anyone equipped with the necessary knowhow, tools and time can build on this knowledge to meaningfully support their immediate community. The importance of the latter cannot be overstated: Different communities face different limitations in the availability of trained staff, medical consumables and machines as well as diagnostic tools. Accordingly, what may be limiting in one place may not be limiting in the next, and any global response must therefore be adjusted to local realities. Here, the many benefits of a FOSH approach allow for fast, local deployment which can bypass traditional production chains to flexibly supply affected areas as they emerge. While this is useful worldwide, it may be particularly important for regions that traditionally have fewer communication links and/or where the medical and scientific infrastructure is generally less well developed [11].

\section{A FOSH approach to supporting global health systems}

Increasingly over recent years, scientists, engineers and hobbyists alike have jointly developed and tested an impressive array of open source and state-of-the art tools that in one way or another touch all aspects of modern biology, medicine and disaster response (e.g., [12-23]). For example, in the wake of the 2011 Fukushima nuclear disaster, Safecast [9] developed FOSH Geiger counters alongside an open access logging system which led to a massive citizenscience driven map of nuclear contamination in the region [9]. Now the same group is stepping up to meet the challenges of COVID-19 [24]. Other community driven FOSH designs relevant to the current situation range from simple tools like DIY masks $[25,26]$ or $3 \mathrm{D}$ printed valves to regulate airflow in ventilator tubes [27] to state-of-the-art scientific instruments for diagnosis such as an automated pipetting robot [28], plate readers [29] as well as a wide range of medical tools and supplies [22]. Diverse further initiatives, including numerous designs for FOSH ventilators [30-38], are well underway. Here, we provide a brief overview of the current state-of-the art in available designs and ongoing community projects aiming to leverage $\mathrm{FOSH}$ to meaningfully contribute to a global response to the current crisis (see also Box 1). In the specific background of COVID-19, we highlight a subset of available projects centered around:

\section{Box 1. An important note of caution and disclaimer}

An important note of caution: When implementing any of the projects mentioned in this article, it is important to critically evaluate the reliability and safety of the design on a case by case basis. While some designs have been extensively tested and verified, others are at best anecdotally verified and are intended for research use only. While this is important in all aspects of FOSH, it becomes imperative when considering diagnostic and medical tools. This should also include careful reference to regulations on control softwares, where applicable [41]. Use of these designs in a clinical setting may be prohibited by local regulations. Notably, the US National Institutes of Health (NIH) 3D print exchange collects a list of designs that have been approved for clinical use in at least one hospital [42].

Disclaimer: The introductory notes on masks and ventilators are based on available literature. The authors have no formal medical training. 
1. Personal protective equipment (PPE) such as masks and visors

2. Patient treatment, focussing on ventilators

3. Diagnosis tools, focussing on scientific equipment and test-kits

Although several projects are listed here, interested readers can find curated lists online that are being updated on a daily basis. At the time of writing these were available $[36,39,40]$

\section{Building personal protective equipment (PPE)}

Buying a facemask off the shelf is becoming increasingly difficult, and people are understandably looking into do-it-yourself (DIY) options that may serve as a useful replacement. Similarly, hospitals are running out of specialised personal protective equipment (PPE) for medical staff, which typically includes both a mask and a visor, alongside specialised clothing and gloves. Here, we will focus on DIY masks and visors (Fig 1, Table 1).

First, it is important to consider what level of protection is required. For example, masks come in many varieties, with different purposes and regulatory standards [48-51]. Some simpler masks (often called surgical masks) are intended to be used by the infected person to reduce spread of infection by catching large droplets, for example after coughing and sneezing. Such masks are fairly easily home-fashioned (e.g. [52], Table 1A), but they are not generally
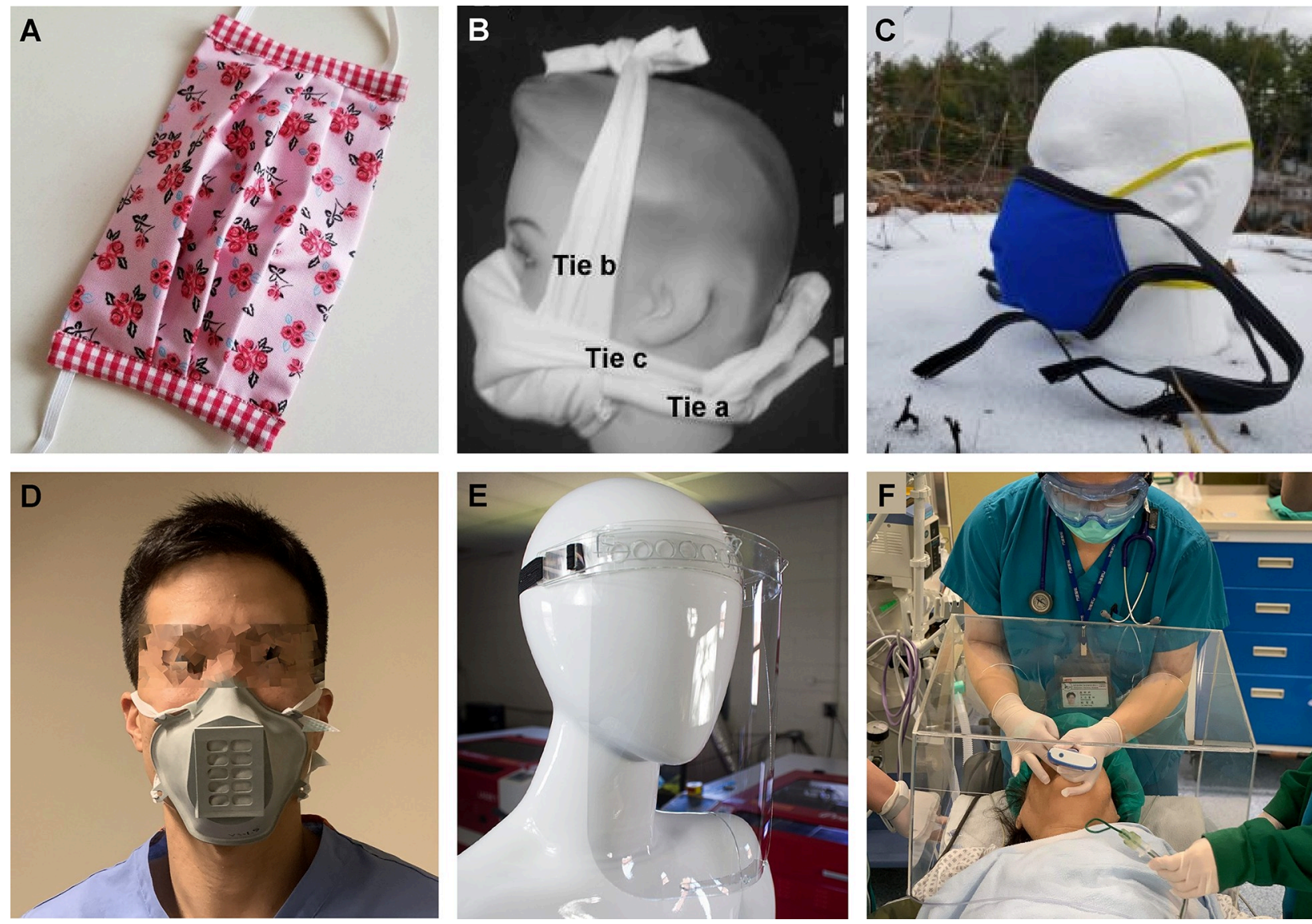

Fig 1. Examples of DIY masks and visors. A, One of many designs for a home-made cloth-mask [43], which to date remain generally untested for effectiveness. B, Somewhat more effective cotton T-shirt based mask [25], C, Impermeable mask cover [44]. D, Stop gap surgical mask (3D printed) [45]. E, Laser-cut face-shield [46]. F, Aerosol box [47]. 
Table 1. Open source and do-it-yourself personal protective equipment. Highlighted are masks, face shields and aerosol boxes.

\begin{tabular}{|c|c|c|c|}
\hline Project Name & License & Type & Note \\
\hline \multicolumn{4}{|l|}{ A, Surgical-type masks } \\
\hline Simple respiratory mask & N/A & Tied & Peer reviewed open access paper \\
\hline $3 \mathrm{D}$ printed face mask from la factoria $3 \mathrm{~d}$ & CC-BY-NC (?) & $3 \mathrm{D}$ printed & license from https://www.thingiverse.com/thing:4225667 \\
\hline Stopgap surgical face mask & CC-BY & $3 \mathrm{D}$ printed & 3D printed mask that has undergone clinical testing \\
\hline Montana Mask & N/A & $3 \mathrm{D}$ printed & Shares more than stl files for 3D printings \\
\hline EDAGmask4all & N/A & $3 \mathrm{D}$ printed & Mask clips to hold textile in place. Only stls are available \\
\hline Bra face mask & N/A & Sewn & Masks made out of bras. \\
\hline CDC face masks & N/A & Sewn & Cloth masks, CDC tutorial \\
\hline Cloth mask with filter & N/A & Sewn & Cloth masks, Georgia Tech tutorials \\
\hline DIY 2 layer cloth mask & N/A & Sewn & Cloth mask with 2 layers \\
\hline DIY sewn facemask & N/A & Sewn & Cloth mask \\
\hline How to sew a face mask & N/A & Sewn & Video tutorial \\
\hline Maker Masks & CC BY 4.0 & Sewn & Multiple designs including a mask protector \\
\hline Paper towel mask & CC BY 3.0 & Paper towel & Paper towel mask \\
\hline \multicolumn{4}{|l|}{ B, N95-type masks } \\
\hline Project $1000 \mathrm{X} 1000$ & CC-BY-NC 4.0 & Filter production & $\begin{array}{l}\text { Initiative to produce air filters for masks } \\
\text { License limits legal use in several places }\end{array}$ \\
\hline Copper 3D & CC-BY-NC 4.0 & $3 \mathrm{D}$ printed & $\begin{array}{l}\text { License limits legal use in several places } \\
\text { Only sharing STL files }\end{array}$ \\
\hline N95decon & Copyright & $\begin{array}{l}\text { Test/study } \\
\text { consortium }\end{array}$ & $\begin{array}{l}\text { "A scientific consortium for data-driven study } \\
\text { of N95 filtering facepiece respirator decontamination" }\end{array}$ \\
\hline Pneumask & CC-BY-NC-SA 4.0 & Snorkel mask & License limits legal use in several places \\
\hline \multicolumn{4}{|l|}{ C, Face protectors } \\
\hline Origami Droplet Face-Shield & CC-BY-SA 4.0 & Laser cut & Shield using only laser cut parts \\
\hline Proto-shield & CC-BY-SA & Laser cut & Shield using only laser cut parts \\
\hline GliaX face protector & GNU-GPL 3.0 & $3 \mathrm{D}$ printed + sheet & \\
\hline$\underline{\text { Prusa face protector }}$ & CC-BY-NC 4.0 & $3 \mathrm{D}$ printed + sheet & License limits legal use in several places \\
\hline Georgia Tech face shields & N/A & Injection mold & \\
\hline Face protector w/o 3D print/laser cut & N/A & Glued & \\
\hline U. Wisconsin-Madison face shield & N/A & Glued & \\
\hline Face protector from water bottle & N/A & Cut-out & \\
\hline Prusa face protector disinfection tests & Copyright & Disinfection tests & Copyright is for webpage. N/A about project license \\
\hline \multicolumn{4}{|l|}{ D, Other PPE } \\
\hline Aerosol box & CC-BY-NC 4.0 & & License limits legal use in several places. \\
\hline Aerosol container & CC-BY-NC 4.0 & & Based on aerosol box listed above \\
\hline Barrier enclosure for endotracheal intubation & Copyright & & \\
\hline
\end{tabular}

https://doi.org/10.1371/journal.pbio.3000730.t001

thought of as an effective form of protection from becoming infected in the first place $[21,22,35]$. Nonetheless, it has been argued that they can reduce the spread of viral particles from infected persons [53]. A recent influential paper [54] elaborated on this point, however this study did not look at SARS-CoV-2, nor at possible spread from asymptomatic carriers (see also [55]). Another study, with four COVID-19 patients, found surgical masks to be ineffective in preventing the spread of SARS-CoV2 [56]. Whether or not the general public should be advised to use surgical-type masks, and under which specific circumstances, is a matter of ongoing debate. At time of writing, the World Health Organisation (WHO) advises:

- If you are healthy, you only need to wear a mask if you are taking care of a person with suspected 2019-nCoV infection. 
- Wear a mask if you are coughing or sneezing.

For an up-to-date summary on the role and use of various types of masks, the reader is referred to their official advice [57]. Notably, the Centre for Disease Control (CDC) in the USA currently recommends wearing masks in public settings where other social distancing measures are difficult to maintain, especially in areas of significant community-based transmission [58]. Moreover, it is possible, and arguably likely, that others will follow suit, especially as the world reopens.

In contrast to surgical masks, so called N95 filtering facepiece respirators (FFRs) are intended to provide a high level of protection to the wearer, and they are for example used by medical staff tending to infected patients. Unlike surgical masks, these are designed to seal against air slipping through gaps between the skin and the mask, and they contain a specialised filter that acts as a physical barrier to particles down to 0.3 microns. This is still bigger than the actual virus ( $~ 0.12$ microns) [59], but substantially smaller than most droplets coming off a sneeze or cough. The performance standards for such masks are tightly regulated [48-51], and any DIY approach to replicating them must take careful reference to these regulations, which may also vary locally. Accordingly, controlled testing of existing and upcoming N95-like FFR prototypes is paramount. Moreover, unless worn correctly they may end up being no more useful than a surgical mask [57]. For protecting the eyes, N95s can be combined with tight-fitting goggles, or a face shield.

Right now there are many DIY designs for various types of masks out there, from simple video tutorials based on napkins, cloth or bra-cups (Table 1A) [60-62] via 3D printed options [63] to designs developed and/or tested in peer-reviewed scientific studies [25,26] (Fig 1). Some are quite effective [25], however to our knowledge to date none fully comply with regulatory standards. Nonetheless, with designs currently being published on a daily basis, this may soon change. Table 1B summarises a subset of DIY N95 projects available at time of writing.

Alternatively, medical staff also use splash-resistant surgical masks (IIR, resistant at 160 $\mathrm{mmHg}$ ), together with a face shield [42]. The latter combination may be easier to build to regulatory standards than N95 masks [56], in part because they do not need to seal tightly against the skin. An online search quickly reveals several designs of face shields (and IIRs [44]) with varying levels of associated testing [64,65] (Table 1C, Fig 1E). For example, 3D Crowd is a UKbased citizen network that is mobilizing volunteers to produce and deliver DIY face protectors to hospitals and health institutions [66]. Through "The Big Print" they have gathered requests for 370,000 units. 80,000 of them are in production by currently over 5,500 volunteers. An alternative approach is based on existing full-face snorkel masks [67] which would effectively serve as a combined mask and visor. Efforts such as these, including their important experimental verification, could easily be scaled with minimal investment. They may also be more easily disinfected for reuse compared to masks $[68,69]$.

In addition, more specialised PPE is also being actively developed. This includes DIY testing booths for diagnostics (virus inactivation before testing needs to be done in a biosafety level 2 facility, BSL2, see below) and DIY aerosol boxes, which are for example used when intubating patients (Fig 1F, Table 1D). Like all medical equipment, these also require regulatory approval [48-51].

\section{Choice of building materials for PPE}

Building materials should be carefully considered. For example, it has been argued that the porosity of 3D printed materials could make them a risky choice for masks as they may allow viral droplets to persist for prolonged periods of time [68]. Possible gaps in the material itself (e.g. due to blistering or imperfect layering during printing) add further room for concern. At 
the time of writing, we are not aware of available data on the above points. Similarly, when laser cutting parts the use of acrylics should be carefully weighed against the need to sanitize it using alcohols or oxygen peroxide which can react with the acrylic. If available, and if the laser cutter at hand can handle it (many cannot), polycarbonate or polyethylene terephthalate glycol (PETG) sheets may present a safer choice. A guide to disinfecting DIY PPE can be found here [70]. Throughout, it also remains important to consider possible quality variations due to the building process itself.

\section{FOSH Ventilators}

Ventilators are medical devices that support or take over patient respiration by delivering air or other gas mixtures. Patients able to breathe on their own are often treated supported by a constant airflow through cannulas or positive pressure masks (PPMs). In more severe cases patients are intubated (insertion of a tube into the patient's airway). Here, some modern ventilators can synchronise the release of gases to any remaining natural breathing attempts. In other cases, ventilators can take over entirely (usually combined with patient sedation). Towards the end of treatment, patients must be carefully weaned off the ventilator. Generally, the use of ventilators brings about risks for infections including pneumonia, lung damage and oxygen toxicity. The latter two of which can sometimes be linked to improper use of the device (e.g. excess air pressure and/or oxygen concentration).

From a technical point of view, ventilators can be as simple as manually operated compressible bags (bag valve masks-BVM), or as complex as fully computerized machines that regulate gas pressure, humidity, gas relative concentrations as well as cycle rate, while taking real-time measurements to monitor patient condition. This added complexity of some more modern systems makes them more suitable for prolonged use, as they better mimic physiological conditions and can be adjusted to specific patient needs. The NIH provides a general overview on ventilators and their use [71], including a wide range of interface types, ventilator functions and other details that are not covered in this article.The UK also recently published their own specifications for ventilators to be used in hospitals [72].

The use of non-invasive systems for patients with COVID-19 in hospitals is currently debated due to their potential to create aerosols which increase the risk of infecting others [73]. Nonetheless some have argued they may have a place under certain circumstances [74], and it is moreover possible that such systems may come into increased use as the situation worsens. However, only invasive systems can fully take over respiration where required.

Already now, and likely more so in the near future, availability of ventilators for patient care is limiting [75-77]. Current efforts to address this impasse include the stopping of elective surgeries to free up existing systems [78], the recommissioning of disused models from storage, and a plea to industry to ramp up production [1,79]. In parallel, diverse groups around the world are rallying their communities to design FOSH-solutions that will help increase the availability of ventilators (Fig 2, Table 2). Some examples include the development of complete and stand-alone systems $[80,81]$, the automation of manual ventilators $[31,33,37]$ and the repair of existing but out-of-use equipment, e.g. with 3D printed replacement parts $[82,83]$. Many projects are actively looking for collaborators with various backgrounds. FOSH ventilators for invasive use will need to implement feedback systems based on sensors that measure pressure, $\mathrm{CO}_{2}$ and oxygen levels, tidal and dead space volumes, and air humidity. These are necessary measurements to know if the machine is doing what is supposed to, and that it is not causing even more harm to the patient. 

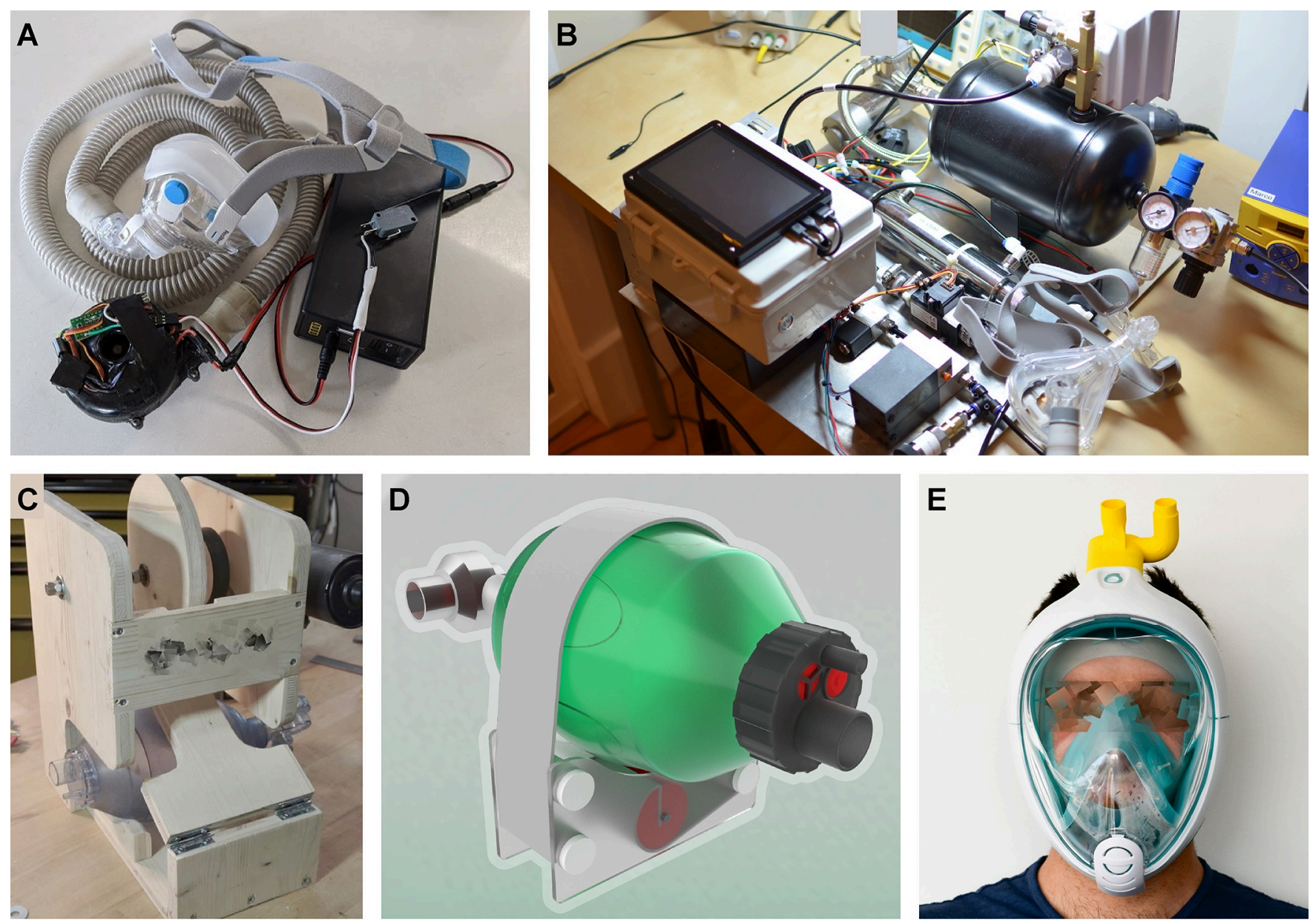

Fig 2. Examples of FOSH ventilators. A, Arduino based PPM system [31]. B, Pandemic ventilator derivative [84]. C, OxyGEN bag automation system [37], D, Prototype rendering from Open Source Ventilator initiative [85]. E, PPM ventilator based on snorkel mask and 3D printed adaptor [86].

https://doi.org/10.1371/journal.pbio.3000730.g002

\section{FOSH approaches in COVID-19 diagnostics}

The WHO recommends that countries should prioritize case finding, testing and isolation as a main strategy to slow down the spread of the virus [87]. This means that testing must be made widely available. The diagnosis of SARS-CoV-2 involves sample collection, usually from nasopharyngeal or oropharyngeal swabs [87], followed by RNA extraction as SARS-CoV-2 is an RNA virus. This typically involves binding the RNA onto silica in specific buffers followed by washing and resuspension. Then, the viral RNA is specifically amplified after reverse transcribing it to DNA. Finally the presence of this DNA is detected, usually by measuring changes in fluorescence intensity or colour. The most common diagnostic procedure involves the use of a commercial kit for RNA extraction, followed by quantitative Reverse Transcription Polymerase Chain Reaction (qRT-PCR) [88] which requires several types of hardware, chemicals and reagents to be deployed and typically takes place in a regulated lab that meets ISO 15189 standards for diagnostics [89]. In addition, RNA extraction or virus inactivation before RNA extraction elsewhere must take place in a BSL2 facility (see above for FOSH PPE designed to substitute a BSL2 facility).

Central testing labs overwhelmingly use automated sample extraction systems and other hardware that have been validated by the FDA and CDC in the US or the national equivalent 
Table 2. Open source ventilators and positive pressure masks.

\begin{tabular}{|c|c|c|c|}
\hline Project Name & License & Type & Note \\
\hline \multicolumn{4}{|l|}{ Ventilators } \\
\hline Open ventilator system initiative & CERN-OHL v2.0 & Ventilator & Documentation to be released \\
\hline Reesistencia & GNU-GPL 3.0 & Ventilator & $\begin{array}{l}\text { Advanced testing stage, updates regularly: } \\
\text { https://twitter.com/ReesistenciaT?s=09 }\end{array}$ \\
\hline Inspire-OpenLung & CERN-OHL v2.0 & Ventilator & Brazilian project, most documentation in Portuguese \\
\hline CITI-OpenLung & CERN-OHL v2.0 & Ventilator & Brazilian project, fork of "Inspire" above \\
\hline Electrónica Reespirator23-17 & MIT / CC-BY-NC 4.0 & Ventilator & Repository is licensed with MIT, but design files are CC-BY-NC 4.0 \\
\hline Open Vent & Permissive coypright (?) & Ventilator & Started as part of the WirvsVirus hackathon \\
\hline MUR & GNU GPL 3.0 & Ventilator & Project in French \\
\hline$\underline{\text { E-Vent }}$ & Not released yet & Ventilator & From MIT. No designs have yet been published. \\
\hline Open Ventilator & N/A & Ventilator & \\
\hline Open Source Ventilator Ireland & GNU-GPL 3.0 & Ventilator & \\
\hline Open Lung & GNU-GPL 3.0 & Ventilator & Canadian project working with Irish Open Source Ventilator above \\
\hline Take a breather (TAB) & N/A & Ventilator & \\
\hline The Pandemic Ventilator & N/A & Ventilator & One of oldest projects, before "reactivation" posts date back to 2011 \\
\hline Pandemic ventilator 2.0 & N/A & Ventilator & Pandemic ventilator spin off \\
\hline Proyecto PVPv1.2 & N/A & Ventilator & Pandemic ventilator spin off, based in Argentina \\
\hline Oxygen & N/A & Ventilator & Spanish project with two versions: one for makers, one for industry \\
\hline RespiraWorks & N/A & Ventilator & Project to document ventilators designs \\
\hline Ventilator firmware & MIT & Ventilator & Brazilian project developing a universal firmware for ventilators \\
\hline Medtronic ventilator & Custom license & Ventilator & License only allows use while WHO PHEIC is in place or Oct 2024 \\
\hline Oxvent & N/A & Ventilator & No designs available yet. Ventilator in testing phase in the UK. \\
\hline$\underline{\text { Vent4us }}$ & N/A & Ventilator & Documentation to be released \\
\hline PAPR & MIT & PPM Ventilator & \\
\hline Mechanical ventilator Milano & N/A & PPM Ventilator & \\
\hline Illinois rapid vent & Custom license & PPM Ventilator & Requires signature of license form \\
\hline Isinnova Easy covid 19 & N/A & PPM Ventilator & Positive pressure mask (PPM) \\
\hline Ifixit repair guides & $\mathrm{CC}$ & Ventilator repair guide & \\
\hline
\end{tabular}

in their local jurisdiction. These are supplied by a small number of large companies (e.g. Qiagen, Roche and Abbott) with vertically integrated business models: only proprietary reagent cartridges and plastic pipette tips for processing samples will typically fit the instruments and there are no or few generic suppliers. This is one of the reasons for acute shortages that have led to calls for donations of reagents and instruments from academic labs to bolster public health efforts [105].

There has also been unprecedented rapid and open sharing of diagnostics and devices through preprint publications, and through informal communication routes among researchers [90,106-108]. For example, agencies in China, Germany, Hong Kong, Japan, Thailand, South Africa and the United States have shared protocols for molecular assays online, including the DNA sequences to detect the virus. Others are now reproducing these in their own labs as well as commercially $[88,109]$. Meanwhile, large sums of money are being invested in universities, public hospitals and the private sector to develop rapid point-of-care (POC) or nearPOC devices to enable scaling of testing in clinics, temporary facilities and even homes.

All reagents and devices used for diagnostics are typically regulated in terms of their manufacture and use, meaning that "home-brew" or DIY solutions are typically not acceptable unless the lab developing and using them is itself certified, and then only under certain conditions. In some jurisdictions regulations are becoming simpler or accelerated during the 
A

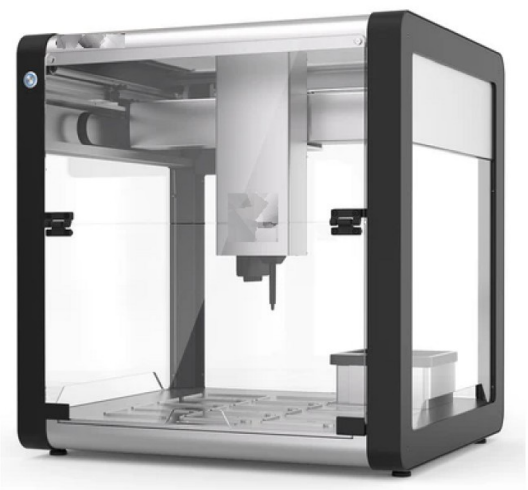

B

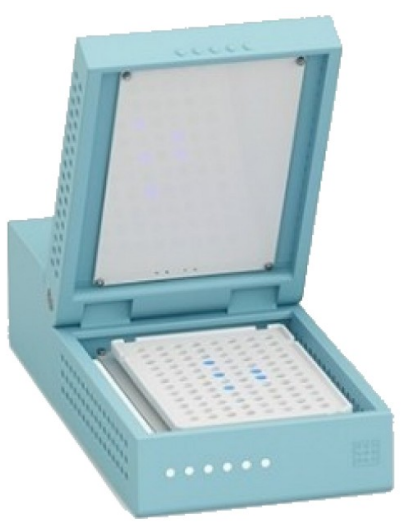

C

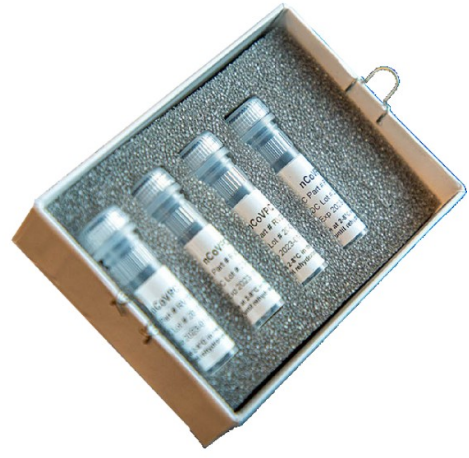

Fig 3. Examples of FOSH designs with potential use in diagnostics. A, OpenTrons [28], a liquid handling robot B, Miriam, an incubator and reader for isothermal amplifications e.g. LAMP [117]. C, US CDC Primer and Probe Kit for diagnostic tests [118].

https://doi.org/10.1371/journal.pbio.3000730.g003

COVID-19 emergency and novel tests are starting to get approval for diagnostic use through the FDA's Emergency Use Authorisation (EUA) scheme [68], WHO's Emergency Use Listing and other national schemes [110]. The transparent and international sharing of protocols at inter-agency level is capable of driving forward testing while academic and commercial projects catch up and apply for emergency approval status.

Community and commercial open source efforts in diagnostic technology to date have focused on four areas: i) open platforms for scaling reactions as exemplified by Opentrons (Fig $3 \mathrm{~A}$ ) [28], an open source lab automation platform that has been working with BP Genomics and the Open Medicine Institute to automate up to 2,400 tests per day and achieve US FDA EUA approval and is now automating COVID-19 testing at the Biomedical Diagnostic Center (CBD) of Hospital Clinic of Barcelona; ii) trying to fill gaps where less attention is being paid by clinical diagnostics companies, such as Chia Bio's Open qPCR (Fig 3B) environmental test kit for surveillance via surface swabs [111]; iii) distributed reproduction of rapidly-published, lab-scale protocols, seen within the OpenCOVID initiative hosted by Just One Giant Lab [39] which involves many community labs worldwide; iv) initiatives such as the Open Enzyme Collection [93], Free Genes [94] and Biomaker Challenge [112] which are investigating new approaches to foundational technologies such as reagents and instrumentation, with a view to building capacity and resources or global science and medicine to face a future pandemic.

These efforts supplement a wide range of existing open hardware and off-patent, generic biotechnologies which could play a role in expanding molecular testing capabilities [7,113116].

In addition, a rapidly accumulating list of publications and pre-prints describe protocols that allow bypassing some of the rate limiting steps in the diagnostic protocol [92,119-121]. For example, RNA extraction can be substituted by simply heating the sample to $95^{\circ} \mathrm{C}$ for 10 minutes [92,121]. Furthermore, the development of alternative diagnostic techniques could help bypass some of the hardware requirements. For example, recently published protocols based on Cas enzymes [106,107,122], ligation-dependent detection [123] and colorimetric RT-LAMP $[124,125]$ obviate the need for a qPCR machine. These protocols require only pipettes and heat blocks or water baths in terms of instrumentation. Readout can then be done via inexpensive lateral flow strips, using a plate reader for which open hardware alternatives exist [29], or even by eye. It is important to note that many of these alternative detection protocols were only shown to work using DNA plasmid controls, or on very small numbers of SARS-CoV-2 patient samples. Therefore, before these are adopted as bona fide diagnostic 
tests, they need to be thoroughly evaluated, followed by local regulatory approval (see above). Companies are being particularly efficient at this [126], but government-funded labs are also now testing and scaling protocols that are independent of commercial kits and this trend has potential to overcome some of the more acute reagent supply chain issues.

Although most of these enzymes and protocols are patent-locked, they would be available for manufacturing and use in areas where patents were not filed, which likely includes many countries in the Global South. Local manufacturing of health technologies depends on the presence of relevant capacity, infrastructure and regulatory frameworks but is promoted by organisations including the WHO, UNIDO, UNCTAD, UNAIDS, UNICEF and The Global Fund [127]. The implementation of low-cost diagnostic technologies in countries with very limited testing resources could be a game changer in the global control of the COVID-19 pandemic, particularly when combined with protocols for RNA extraction that do not depend on commercial kits ([90-92,119,121], and Table 3), and the generation of reagents that can be distributed and stored at room temperature [128]. For this reason, development of rapid diagnostics for use at the community level was \#1 in the WHO's eight immediate research actions agreed as part of their 2019 Novel Coronavirus Global Research and Innovation Forum [129].

The scientific community is coming together to find and implement faster and cheaper diagnostics, which could be instrumental to control the pandemic, particularly in the medium term amid fears of the so-called "second peak" if and when the strict isolation measures put in place in many countries relax. The diagnostic supply chain issues we face currently highlight the risks of under-investment in public diagnostic infrastructure and of vendor lock-in, resulting in reliance on a small number of suppliers. Efforts from the open hardware community to design and produce rate-limiting equipment and reagents (Table 3, Fig 3) could offer a longterm mitigation strategy, allowing rapid scale up of manufacturing of generic designs and recipes, given sufficient political will and investment.

\section{Conclusion and outlook}

In the sections above, we have summarised a subset of current FOSH related initiatives aiming to meet the global challenge of COVID-19. However, our account is by no means comprehensive, and the situation changes daily. Accordingly it remains important to continuously seek up to date information, for example by following live documents curated by the community on various aspects of the FOSH response $[33,37,130]$, and to join key community portals and mailing lists [23,24,130-132].

For brevity, we omitted discussions of related approaches, for example the introduction and modification of existing tools from veterinary care [133]. We did not discuss the important role open-source software and data-collection initiatives can play in understanding and responding to the ongoing and projected situation [134-136]. Also not covered here are other Open Science tools and projects that could help alleviate many problems in the current scenario [137].

Most of the technology discussed above is classed as a medical device when used in a diagnostic or clinical setting; a challenge faced by only a small number of existing open hardware devices and therefore in need of further research. Moving technology to implementation is perhaps the greatest challenge facing these projects, involving consideration of integration into health care systems, supply chain logistics, regulations, legal liability and political will. The urgency of the current situation has led to a relaxation of regulatory processes by the US Food and Drug Administration [138] and the European Union [139], with some open source projects already reaching formal testing stages e.g. the VentRap ventilator from the Open AIRE forum is ready for evaluation by the Department of Health of the Principality of Asturias in Spain [140]. 
Table 3. Diagnostic hardware and reagents with open source alternatives. We have selected FDA/CDC-approved items as an illustration but each country will have its own regulators and agencies with different sets of approved equipment and reagents. Many countries are choosing to simplify or accelerate regulatory approval during the COVID-19 pandemic.

\begin{tabular}{|c|c|c|}
\hline Item & Selected examples of current CDC/FDA-approved items & $\begin{array}{l}\text { Status of Open Source alternatives } \\
\text { Note: these protocols and devices are not yet nationally approved for } \\
\text { diagnostic use in any jurisdiction at the time of writing but they might } \\
\text { be approved for use in specific labs and hospitals. }\end{array}$ \\
\hline RNA Extraction Kit & $\begin{array}{l}\text { Qiagen QIAamp® Viral RNA Mini Kit } \\
\text { Roche MagnaPURE Total Nucleic Acid Kit }\end{array}$ & $\begin{array}{l}\text { There are numerous published protocols to extract viral RNA from } \\
\text { swabs using standard laboratory reagents, for example: } \\
\text { - Trizol and ethanol technique [90] } \\
\text { - Magnetic Bead-based extraction [91] } \\
\text { - Direct RT-PCR from crude samples [92] }\end{array}$ \\
\hline qRT-PCR Mix & 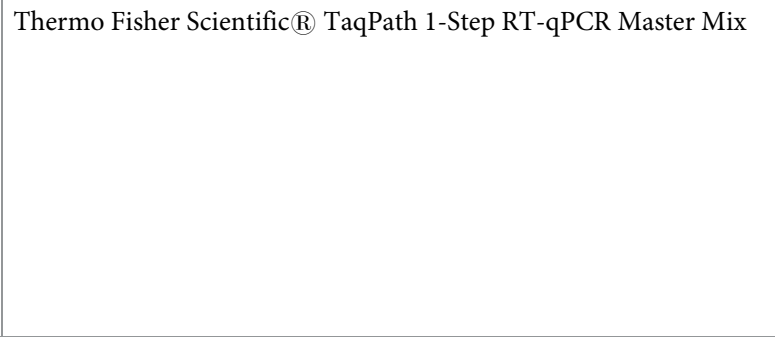 & $\begin{array}{l}\text { Consists of multiple components: } \\
\text { Enzymes (e.g. MMLV reverse transcriptase and DNA polymerase) can } \\
\text { be produced in most labs from DNA vectors. Early versions are already } \\
\text { off-patent and sequences are available from the Open Enzyme } \\
\text { Collection [93] and Free Genes [94]. Later versions are patent-protected } \\
\text { in some jurisdictions but not all. } \\
\text { dNTPs require specific manufacturing capabilities and are currently } \\
\text { readily available commercially in bulk. } \\
\text { Buffers typically use standard lab chemicals and are often published but } \\
\text { may be proprietary. }\end{array}$ \\
\hline Primers & $\begin{array}{l}\text { CDC Primer Set and others approved under FDA Emergency Use } \\
\text { Authorization [95] }\end{array}$ & $\begin{array}{l}\text { Several primer designs have been published as open data and can be } \\
\text { synthesised commercially by any company but for diagnostic use the } \\
\text { company and reagent batches should be validated and approved by the } \\
\text { relevant local regulatory body or used in a regulated lab. }\end{array}$ \\
\hline $\begin{array}{l}\text { Positive Control } \\
\text { RNA/DNA }\end{array}$ & $\begin{array}{l}\text { Positive controls are distributed with CDC kits by the International } \\
\text { Reagent Resource [96]. Genomic RNA positive control available } \\
\text { through BEI Resources [97]. }\end{array}$ & $\begin{array}{l}\text { SARS-COV-2 genome and control sequences are open data and can be } \\
\text { synthesised commercially by any company but must be approved for } \\
\text { diagnostic use. Control reagents are available from [98] in the US and } \\
\text { from relevant agencies or the WHO elsewhere. }\end{array}$ \\
\hline $\begin{array}{l}\text { Automated RNA } \\
\text { Extraction Platform }\end{array}$ & 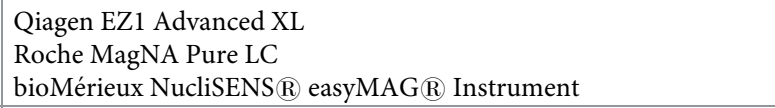 & $\begin{array}{l}\text { OpenTrons [28] is an open source automated platform that can work } \\
\text { with a variety of generic reagents. }\end{array}$ \\
\hline qPCR Thermocycler & $\begin{array}{l}\text { Applied Biosystems } 7500 \text { Fast Dx Real-Time PCR System with SDS } \\
\text { version } 1.4 \text { software }\end{array}$ & $\begin{array}{l}\text { Open qPCR [99] is partially open hardware. There are currently no fully } \\
\text { open alternatives. }\end{array}$ \\
\hline Centrifuges & Refrigerated high-speed centrifuge & $\begin{array}{l}\text { No open designs yet with suitable specifications. Existing centrifuge } \\
\text { designs [100-102] are usually designed for low-speed separation of } \\
\text { plasma at ambient temperature. } \\
\text { Centrifuges and compatible consumables are widely available from } \\
\text { generic manufacturers. }\end{array}$ \\
\hline $\begin{array}{l}\text { Heat block/Water } \\
\text { bath }\end{array}$ & Heat block/Water bath with $30-90^{\circ} \mathrm{C}$ temperature range & $\begin{array}{l}\text { No open heat block designs yet, water baths have been described using } \\
\text { microcontrollers and immersion heaters but the simplest available } \\
\text { solution is use of a sous vide cooking device [103]. } \\
\text { Heat blocks and water baths are widely available from generic } \\
\text { manufacturers. }\end{array}$ \\
\hline Pipettes & $\begin{array}{l}\text { Adjustable micropipettes that meet ISO } 8655 \text { Standard in the range } \\
0.5 \mu \mathrm{l} \text { to } 1,000 \mu \mathrm{l}\end{array}$ & $\begin{array}{l}\text { A 3D-printed open source design is available for an adjustable } \\
\text { micropipette that meets the ISO } 8655 \text { Standard down to } 30 \mu \mathrm{l} \text { [104]. } \\
\text { Note that this volume is not low enough for use in typical in vitro } \\
\text { diagnostic testing. Adjustable micropipettes and compatible } \\
\text { consumables are widely available from generic manufacturers. }\end{array}$ \\
\hline
\end{tabular}

https://doi.org/10.1371/journal.pbio.3000730.t003

In conclusion, FOSH approaches are set to play an important part in the global response to our current situation. To what extent they are able to scale a practical response that directly addresses the current wave of need for medical and diagnostic hardware remains to be seen but that is not their only valuable contribution: they are unlocking large and distributed pools of talent, building knowledge, developing innovative designs and fostering capacity and capabilities to tackle this crisis and future emergencies. Like open source software, FOSH works through the eyes and brains of many. The more people join ongoing projects, or launch their 
own and freely share their progress online, the faster and more effective our united global community will be. The time to join is now.

\section{References}

1. Otte J. Coronavirus: UK manufacturers urged to consider switching to making ventilators. The Guardian. 15 Mar 2020. Available: https://www.theguardian.com/politics/2020/mar/15/coronavirus-ukmanufacturers-urged-to-consider-switching-to-making-ventilators. Accessed 19 Mar 2020.

2. Pound J. 3M CEO: "We're going $24 / 7$ " to ramp up production of masks to meet coronavirus demand. In: CNBC [Internet]. 28 Jan 2020 [cited 19 Mar 2020]. Available: https://www.cnbc.com/2020/01/28/ 3m-ramps-up-production-of-masks-to-meet-coronavirus-demand.html

3. Corera G. UK wary of international market for ventilators. BBC News. 28 Mar 2020. Available: https:// www.bbc.com/news/uk-52074862. Accessed 9 Apr 2020.

4. Saul J, Dowsett S, Baertlein Lisa B. Western supply chains buckle as coronavirus lockdowns spread. Reuters. 23 Mar 2020. Available: https://www.reuters.com/article/us-health-coronavirus-freightidUSKBN21A2PB. Accessed 9 Apr 2020.

5. Cecere L. Planning For The COVID-19 Supply Chain Recovery. In: Forbes [Internet]. 17 Mar 2020 [cited 9 Apr 2020]. Available: https://www.forbes.com/sites/loracecere/2020/03/17/planning-for-thecov-19-supply-chain-recovery/

6. Chagas AM. Haves and have nots must find a better way: The case for open scientific hardware. PLOS Biol. 2018; 16: e3000014. https://doi.org/10.1371/journal.pbio.3000014 PMID: 30260950

7. Baden T, Chagas AM, Gage G, Marzullo T, Prieto-Godino LL, Euler T. Open Labware: 3-D Printing Your Own Lab Equipment. PLOS Biol. 2015; 13: e1002086. https://doi.org/10.1371/journal.pbio. 1002086 PMID: 25794301

8. The Open Hand Project-Home. [cited 19 Mar 2020]. Available: http://www.openhandproject.org/? $L M C L=J X V 7$ as\&LMCL=qGKiRK

9. Safecast. In: Safecast [Internet]. [cited 20 Aug 2018]. Available: https://blog.safecast.org/

10. Pearce JM. Return on investment for open source scientific hardware development. Sci Public Policy. 2016; 43: 192-195. https://doi.org/10.1093/scipol/scv034

11. Maxmen A. How poorer countries are scrambling to prevent a coronavirus disaster. Nature. 2020; 580: 173-174. https://doi.org/10.1038/d41586-020-00983-9 PMID: 32242110

12. Mulberry G, White KA, Vaidya M, Sugaya K, Kim BN. 3D printing and milling a real-time $P C R$ device for infectious disease diagnostics. PLOS ONE. 2017; 12: e0179133. https://doi.org/10.1371/journal. pone. 0179133 PMID: 28586401

13. Kim S-W, Shin H-J, Kay CS, Son SH. A Customized Bolus Produced Using a 3-Dimensional Printer for Radiotherapy. PLOS ONE. 2014; 9: e110746. https://doi.org/10.1371/journal.pone.0110746 PMID: 25337700

14. Jo W, Hoashi Y, Paredes Aguilar LL, Postigo-Malaga M, Garcia-Bravo JM, Min B-C. A low-cost and small USV platform for water quality monitoring. HardwareX. 2019; 6: e00076. https://doi.org/10.1016/ j.ohx.2019.e00076

15. Glatzel S, Hezwani M, Kitson PJ, Gromski PS, Schürer S, Cronin L. A Portable 3D Printer System for the Diagnosis and Treatment of Multidrug-Resistant Bacteria. Chem. 2016; 1: 494-504. https://doi. org/10.1016/j.chempr.2016.08.008

16. Steffens S, Nüßer L, Seiler T-B, Ruchter N, Schumann M, Döring R, et al. A versatile and low-cost open source pipetting robot for automation of toxicological and ecotoxicological bioassays. PLOS ONE. 2017; 12: e0179636. https://doi.org/10.1371/journal.pone.0179636 PMID: 28622373

17. Guillem Camprodon, Óscar González, Víctor Barberán, Máximo Pérez, Viktor Smári, Miguel Ángel de Heras, et al. Smart Citizen Kit and Station: An open environmental monitoring system for citizen participation and scientific experimentation. HardwareX. 2019; 6: e00070. https://doi.org/10.1016/j.ohx. 2019.e00070

18. Sanderson T, Rayner JC. PlasmoTron: an open-source platform for automated culture of malaria parasites. BioRxiv. 2018; 241596. https://doi.org/10.1101/241596

19. Gerum R, Rahlfs H, Streb M, Krauss P, Grimm J, Metzner C, et al. Open(G)PIAS: An Open-Source Solution for the Construction of a High-Precision Acoustic Startle Response Setup for Tinnitus Screening and Threshold Estimation in Rodents. Front Behav Neurosci. 2019; 13. https://doi.org/10.3389/ fnbeh.2019.00140 PMID: 31293403

20. Ferretti J, Di Pietro L, De Maria C. Open-source automated external defibrillator. HardwareX. 2017; 2 : 61-70. https://doi.org/10.1016/j.ohx.2017.09.001 
21. Bücking TM, Hill ER, Robertson JL, Maneas E, Plumb AA, Nikitichev DI. From medical imaging data to 3D printed anatomical models. PLOS ONE. 2017; 12: e0178540. https://doi.org/10.1371/journal.pone. 0178540 PMID: 28562693

22. Niezen G, Eslambolchilar $P$, Thimbleby H. Open-source hardware for medical devices. BMJ Innov. 2016; 2: 78-83. https://doi.org/10.1136/bmjinnov-2015-000080 PMID: 27158528

23. Open Source Toolkit | PLOS. [cited 20 Mar 2020]. Available: https://channels.plos.org/open-sourcetoolkit

24. Safecast-COVID-19. In: Safecast [Internet]. 16 Mar 2020 [cited 20 Mar 2020]. Available: https:// safecast.org/covid19/

25. Dato VM, Hostler D, Hahn ME. Simple Respiratory Mask. Emerg Infect Dis. 2006; 12: 1033-1034. https://doi.org/10.3201/eid1206.051468 PMID: 16752475

26. van der Sande $M$, Teunis $P$, Sabel R. Professional and Home-Made Face Masks Reduce Exposure to Respiratory Infections among the General Population. PLoS ONE. 2008; 3. https://doi.org/10.1371/ journal.pone.0002618 PMID: 18612429

27. Peters J. Volunteers produce 3D-printed valves for life-saving coronavirus treatments. In: The Verge [Internet]. 17 Mar 2020 [cited 20 Mar 2020]. Available: https://www.theverge.com/2020/3/17/ 21184308/coronavirus-italy-medical-3d-print-valves-treatments

28. Opentrons | Open-source Pipetting Robots for Biologists. [cited 17 Aug 2019]. Available: https:// opentrons.com/

29. Szymula KP, Magaraci MS, Patterson M, Clark A, Mannickarottu SG, Chow BY. An Open-Source Plate Reader. Biochemistry. 2019; 58: 468-473. https://doi.org/10.1021/acs.biochem.8b00952 PMID: 30511843

30. ApolloBVM. In: Google Docs [Internet]. [cited 20 Mar 2020]. Available: https://docs.google.com/ document/d/1-DRXnVkJOIDCmvTzh-DgWDxeLSrZTiBYyHOypzv8tNA

31. Lee J. jcl5m1/ventilator. 2020. Available: https://github.com/jcl5m1/ventilator

32. panventFollow. The Pandemic Ventilator. In: Instructables [Internet]. [cited 21 Mar 2020]. Available: https://www.instructables.com/id/The-Pandemic-Ventilator/

33. Trevor Smale / Open Source Ventilator-OpenLung BVM Ventilator. In: GitLab [Internet]. [cited 20 Mar 2020]. Available: https://gitlab.com/TrevorSmale/OSV-OpenLung

34. O’Donnell R. RuairiSpain/openVentilator. 2020. Available: https://github.com/RuairiSpain/ openVentilator

35. Publnv/covid19-vent-list. Public Invention; 2020. Available: https://github.com/Publnv/covid19-ventlist

36. Corona COVID19 opensource. In: Google Docs [Internet]. [cited 23 Mar 2020]. Available: https://docs. google.com/document/d/1UH7AZWH3riztt1rTQZRHC-cZYGTPFPyavOxXcvadU9M

37. Welcome to the OxyGEN project. In: OxyGEN [Internet]. 20 Mar 2020 [cited 20 Mar 2020]. Available: https://www.oxygen.protofy.xyz/

38. coronamakers ventilator. [cited 23 Mar 2020]. Available: https://www.coronavirusmakers.org/index. php/es/prototipos/hardware

39. JOGL—Just One Giant Lab -COVID19. In: JOGL_Just One Giant Lab [Internet]. [cited 22 Mar 2020]. Available: https://app.jogl.io/program/opencovid19

40. CovidX. [cited 15 Apr 2020]. Available: https://www.covidx.org/covid19-open-innovation-index

41. Twomey J. Know Your Regulations Before You Design Medical Electronics. In: Electronic Design [Internet]. 11 Nov 2013 [cited 9 Apr 2020]. Available: https://www.electronicdesign.com/powermanagement/article/21798672/know-your-regulations-before-you-design-medical-electronics

42. COVID-19 Response / NIH 3D Print Exchange. [cited 11 Apr 2020]. Available: https://3dprint.nih.gov/ collections/covid-19-response

43. 5 Free DIY Face Mask Tutorials using fabric-LAST RESORT ONLY. In: SewCanShe | Free Sewing Patterns and Tutorials [Internet]. [cited 20 Mar 2020]. Available: https://www.sewcanshe.com/blog/5free-diy-face-mask-tutorials-using-fabric

44. MakerMask: Science-Based Mask Designs for Community Makers. In: MakerMask [Internet]. [cited 11 Apr 2020]. Available: https://makermask.org/

45. Stopgap Surgical Face Mask (SFM) | NIH 3D Print Exchange. [cited 11 Apr 2020]. Available: https:// 3dprint.nih.gov/discover/3dpx-013429

46. Proto Shield. In: Protohaven [Internet]. 27 Mar 2020 [cited 11 Apr 2020]. Available: https://www. protohaven.org/proto-shield/

47. Aerosol Box—Design. [cited 11 Apr 2020]. Available: https://sites.google.com/view/aerosolbox/design 
48. RSG Safety-EN Standards \& Approvals. [cited 9 Apr 2020]. Available: https://www.rsgsafety.com/ en/en-standards-approvals

49. European standards for medical supplies freely available. In: European Commission-European Commission [Internet]. [cited 9 Apr 2020]. Available: https://ec.europa.eu/commission/presscorner/ detail/en/IP_20_502

50. Health $C$ for D and R. N95 Respirators and Surgical Masks (Face Masks). FDA. 2020 [cited 9 Apr 2020]. Available: https://www.fda.gov/medical-devices/personal-protective-equipment-infectioncontrol/n95-respirators-and-surgical-masks-face-masks

51. COVID-19 personal protective equipment (PPE). In: GOV.UK [Internet]. [cited 9 Apr 2020]. Available: https://www.gov.uk/government/publications/wuhan-novel-coronavirus-infection-prevention-andcontrol/covid-19-personal-protective-equipment-ppe

52. OSCMS—Face Masks. In: Google Docs [Internet]. [cited 9 Apr 2020]. Available: https://docs.google. com/document/d/1-71FJTml1Q1kjSDLP0EegMERjg_0kk_7UfaRE4r66Mg

53. Davies A, Thompson K-A, Giri K, Kafatos G, Walker J, Bennett A. Testing the efficacy of homemade masks: would they protect in an influenza pandemic? Disaster Med Public Health Prep. 2013; 7 : 413418. https://doi.org/10.1017/dmp.2013.43 PMID: 24229526

54. Leung NHL, Chu DKW, Shiu EYC, Chan K-H, McDevitt JJ, Hau BJP, et al. Respiratory virus shedding in exhaled breath and efficacy of face masks. Nat Med. 2020; 1-5. https://doi.org/10.1038/s41591019-0740-8

55. Fineberg H. Read "Rapid Expert Consultation on the Possibility of Bioaerosol Spread of SARS-CoV-2 for the COVID-19 Pandemic (April 1, 2020)" at NAP.edu. 2020. https://doi.org/10.17226/25769

56. Bae S, Kim M-C, Kim JY, Cha H-H, Lim JS, Jung J, et al. Effectiveness of Surgical and Cotton Masks in Blocking SARS-CoV-2: A Controlled Comparison in 4 Patients. Ann Intern Med. 2020 [cited 9 Apr 2020]. https://doi.org/10.7326/M20-1342 PMID: 32251511

57. When and how to use masks. [cited 21 Mar 2020]. Available: https://www.who.int/emergencies/ diseases/novel-coronavirus-2019/advice-for-public/when-and-how-to-use-masks

58. CDC. Coronavirus Disease 2019 (COVID-19). In: Centers for Disease Control and Prevention [Internet]. 11 Feb 2020 [cited 15 Apr 2020]. Available: https://www.cdc.gov/coronavirus/2019-ncov/preventgetting-sick/cloth-face-cover.html

59. Zhu N, Zhang D, Wang W, Li X, Yang B, Song J, et al. A Novel Coronavirus from Patients with Pneumonia in China, 2019. N Engl J Med. 2020; 382: 727-733. https://doi.org/10.1056/NEJMoa2001017 PMID: 31978945

60. DIY: How to sew Face Mask / NO Sewing Machine! Available: https://www.youtube.com/watch?v= xNOHH2Zb2hY

61. DIY Homemade Surgical Face Mask. Available: https://www.youtube.com/watch?v=fMA7a6xO3G0

62. DIY FACE MASK GAMIT ANG LUMANG BRA / HOW TO MAKE FACE MASK USING OLD BRA. Available: https://www.youtube.com/watch?v=66RcXIMxiHc

63. COVID-19 Response. In: Lowell Makes [Internet]. 20 Mar 2020 [cited 22 Mar 2020]. Available: https:// lowellmakes.com/covid-19-response/

64. GliaX/faceshield. Glia Free Medical hardware; 2020. Available: https://github.com/GliaX/faceshield

65. Prusa Protective Face Shield—RC2. In: PrusaPrinters [Internet]. [cited 22 Mar 2020]. Available: https://www.prusaprinters.org/prints/25857-prusa-protective-face-shield-rc2

66. 3D Crowd UK. In: 3DCrowd UK [Internet]. [cited 10 Apr 2020]. Available: https://www.3dcrowd.uk

67. Reusable Full-Face Snorkel Mask PPE Project. In: Google Docs [Internet]. [cited 21 Mar 2020]. Available: https://docs.google.com/document/d/1J22le3dBZBnNDXGIJLRb38z7v7LaOjKfDeN9fOtFeKY

68. From Design to Mass 3D printing of Medical Shields in Three Days. In: Prusa Printers [Internet]. 18 Mar 2020 [cited 20 Mar 2020]. Available: https://blog.prusaprinters.org/from-design-to-mass-3dprinting-of-medical-shields-in-three-days/

69. Pearce JM. Maximizing returns for public funding of medical research with open-source hardware. Health Policy Technol. 2017; 6: 381-382. https://doi.org/10.1016/j.hlpt.2017.09.001

70. Prusa Face Shield disinfection. In: Prusa Knowledgebase [Internet]. [cited 9 Apr 2020]. Available: https://help.prusa3d.com/en/article/prusa-face-shield-disinfection_125457

71. Ventilator/Ventilator Support | National Heart, Lung, and Blood Institute (NHLBI). [cited 20 Mar 2020]. Available: https://www.nhlbi.nih.gov/health-topics/ventilatorventilator-support

72. Specification for ventilators to be used in UK hospitals during the coronavirus (COVID-19) outbreak. In: GOV.UK [Internet]. [cited 22 Mar 2020]. Available: https://www.gov.uk/government/publications/ specification-for-ventilators-to-be-used-in-uk-hospitals-during-the-coronavirus-covid-19-outbreak 
73. Ñamendys-Silva SA. Respiratory support for patients with COVID-19 infection. Lancet Respir Med. 2020; 0. https://doi.org/10.1016/S2213-2600(20)30110-7 PMID: 32145829

74. Coronavirus disease 2019 (COVID-19) - Treatment algorithm | BMJ Best Practice. [cited 21 Mar 2020]. Available: https://bestpractice.bmj.com/topics/en-gb/3000168/treatment-algorithm

75. As The Pandemic Spreads, Will There Be Enough Ventilators? In: NPR.org [Internet]. [cited 19 Mar 2020]. Available: https://www.npr.org/sections/health-shots/2020/03/14/815675678/as-the-pandemicspreads-will-there-be-enough-ventilators

76. Coronavirus in US: Medical experts fear ventilator shortage for COVID-19 patients. In: ABC7 San Francisco [Internet]. 18 Mar 2020 [cited 19 Mar 2020]. Available: https://abc7news.com/6024501/

77. Urgent moves to build ventilators here. In: Newsroom [Internet]. 19 Mar 2020 [cited 19 Mar 2020]. Available: https://www.newsroom.co.nz/2020/03/19/1089022

78. Five ways hospitals will change to tackle virus. BBC News. 15 Mar 2020. Available: https://www.bbc. com/news/uk-51898207. Accessed 19 Mar 2020.

79. Coronavirus (COVID-19): ventilator supply specification. In: GOV.UK [Internet]. [cited 21 Mar 2020]. Available: https://www.gov.uk/government/publications/coronavirus-covid-19-ventilator-supplyspecification

80. Pandemic Ventilator Project. [cited 20 Mar 2020]. Available: https://panvent.blogspot.com/

81. Al Husseini AM, Lee HJ, Negrete J, Powelson S, Servi AT, Slocum AH, et al. Design and Prototyping of a Low-Cost Portable Mechanical Ventilator. J Med Devices. 2010; 4: 027514. https://doi.org/10. $1115 / 1.3442790$

82. [Updating] Italian hospital saves Covid-19 patients lives by 3D printing valves for reanimation devices. In: 3D Printing Media Network [Internet]. 14 Mar 2020 [cited 21 Mar 2020]. Available: https://www. 3dprintingmedia.network/covid-19-3d-printed-valve-for-reanimation-device/

83. Ventilator Repair. In: iFixit [Internet]. [cited 23 Mar 2020]. Available: https://www.ifixit.com/Device/ Ventilator

84. Mascobot. Mascobot/pandemic-ventilator-2.0. 2020. Available: https://github.com/Mascobot/ pandemic-ventilator-2.0

85. Open Source Ventilator. [cited 20 Mar 2020]. Available: https://opensourceventilator.ie/

86. isinnova. Easy-Covid19 ENG. In: Isinnova [Internet]. [cited 11 Apr 2020]. Available: https://www. isinnova.it/easy-covid19-eng/

87. Laboratory testing for 2019 novel coronavirus (2019-nCoV) in suspected human cases. [cited 22 Mar 2020]. Available: https://www.who.int/publications-detail/laboratory-testing-for-2019-novelcoronavirus-in-suspected-human-cases-20200117

88. National laboratories. [cited 21 Mar 2020]. Available: https://www.who.int/emergencies/diseases/ novel-coronavirus-2019/technical-guidance/laboratory-guidance

89. ISO 15189:2012(en), Medical laboratories —Requirements for quality and competence. [cited $21 \mathrm{Mar}$ 2020]. Available: https://www.iso.org/obp/ui/\#iso:std:iso:15189:ed-3:v2:en

90. Won J, Lee S, Park M, Kim TY, Park MG, Choi BY, et al. Development of a Laboratory-safe and Lowcost Detection Protocol for SARS-CoV-2 of the Coronavirus Disease 2019 (COVID-19). [cited 22 Mar 2020]. https://doi.org/10.5607/en20009 PMID: 32156101

91. Zhao Z, Cui H, Song W, Ru X, Zhou W, Yu X. A simple magnetic nanoparticles-based viral RNA extraction method for efficient detection of SARS-CoV-2. bioRxiv. 2020; 2020.02.22.961268. https:// doi.org/10.1101/2020.02.22.961268

92. Bruce EA, Tighe S, Hoffman JJ, Laaguiby P, Gerrard DL, Diehl SA, et al. RT-qPCR DETECTION OF SARS-CoV-2 RNA FROM PATIENT NASOPHARYNGEAL SWAB USING QIAGEN RNEASY KITS OR DIRECTLY VIA OMISSION OF AN RNA EXTRACTION STEP. bioRxiv. 2020; 2020.03.20.001008. https://doi.org/10.1101/2020.03.20.001008

93. Open Enzyme Collection-Open Bioeconomy Lab. [cited 22 Mar 2020]. Available: https:// openbioeconomy.org/projects/open-enzyme-collections/

94. Free Genes | BioBricks Foundation. [cited 22 Mar 2020]. Available: https://biobricks.org/freegenes/

95. Health $C$ for D and R. Emergency Use Authorizations. FDA. 2020 [cited 22 Mar 2020]. Available: http://www.fda.gov/medical-devices/emergency-situations-medical-devices/emergency-useauthorizations

96. International Reagent Resource > Home. [cited 22 Mar 2020]. Available: https://www. internationalreagentresource.org/Home.aspx

97. BEI Resources. In: Biodefense and Emerging Infections Research Resources Repository. [cited 22 Mar 2020]. Available: https://www.beiresources.org/ 
98. Wuhan coronavirus (2019-nCoV/Covid-19) assays and controls | IDT. [cited 22 Mar 2020]. Available: https://eu.idtdna.com/pages/education/decoded/article/assays-and-sequences-for-2019-ncovdetection-and-vaccine-development

99. Open qPCR Machine: Your Personal Real-Time PCR Machine | Chai. [cited 19 Mar 2020]. Available: https://www.chaibio.com/openqpcr

100. Boheemen P van. PieterVanBoheemen/RWXBioFuge. 2017. Available: https://github.com/ PieterVanBoheemen/RWXBioFuge

101. Warejoncas Z, Stewart C, Giannini J. An Inexpensive, Open-Source Mini-Centrifuge. Am Biol Teach. 2018; 80: 451-456. https://doi.org/10.1525/abt.2018.80.6.451

102. Sule SS, Petsiuk AL, Pearce JM. Open Source Completely 3-D Printable Centrifuge. Instruments. 2019; 3: 30. https://doi.org/10.3390/instruments3020030

103. Rybolt TR, Mebane RC. Economical High-Temperature Water Bath Control and Monitoring with a Sous Vide Cooking Device. J Chem Educ. 2018; 95: 1402-1405. https://doi.org/10.1021/acs. jchemed.8b00163

104. Brennan MD, Bokhari FF, Eddington DT. Open Design 3D-Printable Adjustable Micropipette that Meets the ISO Standard for Accuracy. Micromachines. 2018; 9: 191. https://doi.org/10.3390/ mi9040191 PMID: 30424124

105. Shortage of RNA extraction kits hampers efforts to ramp up COVID-19 coronavirus testing. In: Chemical \& Engineering News [Internet]. [cited 9 Apr 2020]. Available: https://cen.acs.org/analyticalchemistry/diagnostics/Shortage-RNA-extraction-kits-hampers/98/web/2020/03

106. Broughton JP, Deng X, Yu G, Fasching CL, Singh J, Streithorst J, et al. Rapid Detection of 2019 Novel Coronavirus SARS-CoV-2 Using a CRISPR-based DETECTR Lateral Flow Assay. medRxiv. 2020; 2020.03.06.20032334. https://doi.org/10.1101/2020.03.06.20032334

107. Zhang F, Abudayyeh $O O$, Gootenberg JS. A protocol for detection of COVID-19 using CRISPR diagnostics.: 8.

108. Pang J, Wang MX, Ang IYH, Tan SHX, Lewis RF, Chen JI-P, et al. Potential Rapid Diagnostics, Vaccine and Therapeutics for 2019 Novel Coronavirus (2019-nCoV): A Systematic Review. J Clin Med. 2020; 9: 623. https://doi.org/10.3390/jcm9030623 PMID: 32110875

109. CDC 2019-nCoV Real-Time RT-PCR Diagnostic Panel. Available: https:/www.cdc.gov/coronavirus/ 2019-ncov/downloads/List-of-Acceptable-Commercial-Primers-Probes.pdf

110. SARS-CoV-2 diagnostic pipeline. In: FIND [Internet]. [cited 22 Mar 2020]. Available: https://www. finddx.org/covid-19/pipeline/

111. OSHWA Certification. [cited 22 Mar 2020]. Available: https://certification.oshwa.org/

112. Biomaker.org. In: Biomaker.org [Internet]. [cited 22 Mar 2020]. Available: https://www.biomaker.org

113. Kong DS, Thorsen TA, Babb J, Wick ST, Gam JJ, Weiss R, et al. Open-source, community-driven microfluidics with Metafluidics. Nat Biotechnol. 2017; 35: 523-529. https://doi.org/10.1038/nbt.3873 PMID: 28591125

114. Nguyen T, Zoëga Andreasen S, Wolff A, Duong Bang D. From Lab on a Chip to Point of Care Devices: The Role of Open Source Microcontrollers. Micromachines. 2018; 9. https://doi.org/10.3390/ mi9080403 PMID: 30424336

115. Myers FB, Henrikson RH, Bone J, Lee LP. A Handheld Point-of-Care Genomic Diagnostic System. PLOS ONE. 2013; 8: e70266. https://doi.org/10.1371/journal.pone.0070266 PMID: 23936402

116. Open-Source Lab. Elsevier; 2014. https://doi.org/10.1016/C2012-0-07249-3

117. Terrijärvi J. Isothermal real time DNA amplification instrument. 2019 [cited 23 Mar 2020]. Available: https://lutpub.lut.fi/handle/10024/159386

118. CDC. FAQ for Diagnostic Tools and Virus. In: Centers for Disease Control and Prevention [Internet] 11 Feb 2020 [cited 23 Mar 2020]. Available: https:/www.cdc.gov/coronavirus/2019-ncov/lab/toolvirus-requests.html

119. Sentmanat M, Kouranova E, Cui X. One-step RNA extraction for RT-qPCR detection of 2019-nCoV. bioRxiv. 2020; 2020.04.02.022384. https://doi.org/10.1101/2020.04.02.022384

120. Ladha A, Joung J, Abudayyeh OO, Gootenberg JS, Zhang F. A 5-min RNA preparation method for COVID-19 detection with RT-qPCR.: 6.

121. Fomsgaard AS, Rosenstierne MW. An alternative workflow for molecular detection of SARS-CoV-2escape from the NA extraction kit-shortage. medRxiv. 2020; 2020.03.27.20044495. https://doi.org/10. 1101/2020.03.27.20044495

122. Lucia C, Federico P-B, Alejandra GC. An ultrasensitive, rapid, and portable coronavirus SARS-CoV-2 sequence detection method based on CRISPR-Cas12. bioRxiv. 2020; 2020.02.29.971127. https://doi. org/10.1101/2020.02.29.971127 
123. Woo CH, Jang S, Shin G, Jung GY, Lee JW. Sensitive one-step isothermal detection of pathogenderived RNAs. medRxiv. 2020; 2020.03.05.20031971. https://doi.org/10.1101/2020.03.05.20031971

124. Rapid Molecular Detection of SARS-CoV-2 (COVID-19) Virus RNA Using Colorimetric LAMP | medRxiv. [cited 22 Mar 2020]. Available: https://www.medrxiv.org/content/10.1101/2020.02.26.20028373v1

125. Rapid colorimetric detection of COVID-19 coronavirus using a reverse tran-scriptional loop-mediated isothermal amplification (RT-LAMP) diagnostic plat-form: iLACO | medRxiv. [cited 22 Mar 2020]. Available: https://www.medrxiv.org/content/10.1101/2020.02.20.20025874v1

126. Detect COVID-19 in as Little as 5 Minutes. [cited 11 Apr 2020]. Available: https://www.abbott.com/ corpnewsroom/product-and-innovation/detect-covid-19-in-as-little-as-5-minutes.html

127. Interagency statement on promoting local production of medicines and other health technologies. [cited 9 Apr 2020]. Available: https://www.unaids.org/en/resources/presscentre/ pressreleaseandstatementarchive/2019/may/20190524_local-production-medicines

128. Xu J, Wang J, Zhong Z, Su X, Yang K, Chen Z, et al. Room-temperature-storable PCR Mixes for SARS-CoV-2 Detection. bioRxiv. 2020; 2020.04.07.029934. https://doi.org/10.1101/2020.04.07. 029934

129. WHO COORDINATED GLOBAL RESEARCH ROADMAP: 2019 NOVEL CORONAVIRUS. Available: https://www.who.int/blueprint/priority-diseases/key-action/Coronavirus_Roadmap_V9.pdf

130. JOGL_Just One Giant Lab. In: JOGL_Just One Giant Lab [Internet]. [cited 20 Mar 2020]. Available: https://app.jogl.io/project/121\#news

131. GOSH Community Forum. In: GOSH Community Forum [Internet]. [cited 20 Aug 2018]. Available: http://forum.openhardware.science/

132. Help (Corona Virus). In: The Mantis 3D Printer [Internet]. [cited 21 Mar 2020]. Available: https://www. mantis3dprinter.com/help

133. Vets Offer Animal Ventilators to Ease U.K. Virus Crisis. Bloomberg.com. 17 Mar 2020. Available: https://www.bloomberg.com/news/articles/2020-03-17/vets-ready-to-offer-animal-ventilators-to-easeu-k-virus-crisis. Accessed 21 Mar 2020.

134. Wu T, Ge X, Yu G, Hu E. Open-source analytics tools for studying the COVID-19 coronavirus outbreak. medRxiv. 2020; 2020.02.25.20027433. https://doi.org/10.1101/2020.02.25.20027433

135. Teams $\mathrm{G}$ and $\mathrm{H}$ developments, Nekrutenko A, Pond SLK. No more business as usual: agile and effective responses to emerging pathogen threats require open data and open analytics. bioRxiv. 2020; 2020.02.21.959973. https://doi.org/10.1101/2020.02.21.959973

136. COVID-19 tracker. [cited 22 Mar 2020]. Available: https://vac-Ishtm.shinyapps.io/ncov_tracker/

137. Havemann J, Bezuidenhout L, Achampong J, Akligoh $\mathrm{H}$, Ayodele $\mathrm{O}$, Hussein $\mathrm{S}$, et al. Harnessing the Open Science infrastructure for an efficient African response to COVID-19 [preprint]. 2020 [cited 15 Apr 2020]. https://doi.org/10.5281/zenodo.3733768

138. Commissioner O of the. Coronavirus Disease 2019 (COVID-19). FDA. 2020 [cited 22 Mar 2020]. Available: http://www.fda.gov/emergency-preparedness-and-response/mcm-issues/coronavirus-disease2019-covid-19

139. COMMISSION RECOMMENDATION (EU) 2020/403 of 13 March 2020 on conformity assessment and market surveillance procedures within the context of the COVID-19 threat. Available: https://eurlex.europa.eu/legal-content/EN/TXT/PDF/?uri=CELEX:32020H0403\&from=EN

140. Resumen del día 20/03/2020 —Viseras en marcha y varios respiradores avanzando! In: Forum A.I. RE. [Internet]. [cited 23 Mar 2020]. Available: https://foro.coronavirusmakers.org/index.php? $p=/$ discussion/366/resumen-del-dia-20-03-2020-viseras-en-marcha-y-varios-respiradores-avanzando 